Article

\title{
Acquiring L1-English L2-Spanish Code-Switching: The Role of Exposure to Language Mixing
}

\author{
Bryan Koronkiewicz \\ Department of Modern Languages and Classics, The University of Alabama, Tuscaloosa, AL 35487-0246, USA; \\ bjkoronkiewicz@ua.edu; Tel.: +1-205-348-5720 \\ Received: 14 January 2018; Accepted: 6 July 2018; Published: 12 July 2018 \\ check for \\ updates
}

\begin{abstract}
This paper explores the code-switching behavior of second language (L2) bilinguals as a lens into the development of their L2 linguistic systems. Specifically, it investigates the acceptability judgments of L1-English L2-Spanish bilinguals on intra-sentential code-switching, comparing those judgments to a group of Spanish-English bilinguals who acquired both languages as an L1. The particular issues of proficiency and bilingual language behavior are analyzed, testing whether either factor has an effect on L2 code-switching intuitions. The results suggest that both proficiency and bilingual language behavior are relevant. L2 bilinguals with an intermediate/advanced proficiency level of Spanish were more likely to align with 2L1 bilinguals with regard to codeswitching judgments, as were L2 bilinguals who reported prior experience with language mixing. L2 bilinguals with lower proficiency in Spanish, as well as those who reported never engaging in code-switching, however, were more likely to diverge from the 2L1 bilinguals in their judgments.
\end{abstract}

Keywords: code-switching; bilingualism; Second Language Acquisition; syntax; Spanish; English

\section{Introduction}

Code-switching (CS) is a bilingual phenomenon commonly defined as the fluid alternation between languages during conversation (Poplack 1980). This paper focuses on intra-sentential CS-language mixing that occurs within the same sentence. Consistent findings from CS research show that it is not an artifact of bilingual deficiency or language detrition. Rather, it is a rule-governed phenomenon prevalent in the speech of highly proficient bilinguals. Consider, for instance, the examples of Spanish-English CS in (1).

1. ase hombre ordered a glass of water.

That guy

'That guy ordered a glass of water.'

b. *Él ordered a glass of water.

$\mathrm{He}$

'He ordered a glass of water.'

Here we see two similar switches from Spanish into English. The only distinction between the two sentences is that in one instance a full lexical Determiner Phrase (DP), ese hombre 'that guy', occupies the subject position (1a), whereas in the other we have a personal pronoun, él 'he' (1b). This minor difference has a crucial consequence: the switch from a Spanish lexical DP to a finite English verb is considered grammatical, whereas the switch between a Spanish pronoun and a finite English verb is not. This distinction between switching lexical DPs and pronouns (regardless of the language direction) has been known for quite some time (Gumperz 1977; Lipski 1978; Timm 1975; among others), and it is 
just one example of a number of commonly attested, rule-governed instances of (un)grammaticality in CS.

Although there is a large body of work that attempts to account for the structural constraints on CS, the CS of second language (L2) bilinguals in particular has received less attention. In many cases, L2 bilinguals are excluded entirely, focusing solely on bilinguals who learned both languages from birth (i.e., both as an L1). Moreover, researchers who do include L2 bilinguals often have them form part of a broad umbrella "bilingual" group. In these cases, since the L2 data are not separated from those of 2L1 bilinguals, no information can be gleaned that is specific to L2 speakers.

Nonetheless, there are some notable exceptions. For example, L2 CS has been analyzed with regard to language dominance (Fernández Fuertes et al. 2016; Liceras et al. 2016) and L2 proficiency (Giancaspro 2015; Liceras et al. 2008; Toribio 2001). This line of work highlights the fact that there are crucial differences in the structure of CS across diverse bilingual groups, and there is a need to further explore these contrasts with L2 speakers. Within the field of Second Language Acquisition (SLA) specifically, though, L2 CS has more frequently been discussed with regard to pedagogy. That is to say, CS has been looked at when ascertaining to what level language learners do and/or should use their L1 in the L2 classroom (Hancock 1997, Macaro 2005; among others).

Although few investigations have explicitly analyzed CS with regard to the development of the L2 linguistic system, Toribio (2001), Giancaspro (2015), and Fernández Fuertes et al. (2016) all found evidence that it is possible for L2 bilinguals to acquire rule-governed restraints on CS. In these studies, proficiency or dominance was shown to play a critical role. Other possible factors have yet to be investigated, including the role of actual exposure to (and/or production of) language mixing. The current study tackles this specific issue as it relates to L2 CS, with the results suggesting that exposure to language mixing, in conjunction with increased proficiency, aids in L2 bilinguals in acquiring well-formedness judgments for CS.

\section{L2 Code-Switching}

\subsection{Code-Switching as a Lens into the Developing L2 System}

As with 2L1 bilinguals, L2 CS should not be considered a linguistic deficiency where language mixing occurs because the individual cannot maintain monolingual communication. It is true that CS can serve as a linguistic crutch to fill in gaps for L2 learners at the beginning levels of proficiency. However, the same way L2 speakers can learn to style shift given different sociolinguistic contexts (Tarone 1982, as cited in Ellis 1994), we can imagine them also learning to shift between languages, even in the same sentence, if given an appropriate bilingual context.

Recall that CS is a rule-governed phenomenon practiced by highly proficient bilinguals. That is to say, language mixing is understood as part of the grammatical competence of bilinguals. Although SLA researchers have explored countless other domains of grammar with regard to L2 acquisition, as it stands, there is little research that investigates L2 CS as a lens into the development of a non-native linguistic system. This study contributes to the limited line of research that aims to explain whether L2 bilinguals are able to acquire restrictions on CS, and, if so, how they are able to do so.

\subsection{L2 Code-Switching and the Functional Head Constraint}

The first work to explicitly examine L2 bilinguals with regard to their development of CS intuitions was Toribio (2001), specifically asking whether they were able to acquire well-formedness restrictions on CS. The study explored whether the predictions of the Functional Head Constraint (FHC), as proposed by Belazi et al. (1994), align with the acceptability judgments of L1-English L2-Spanish bilinguals.

The FHC is a generative model of CS that marks lexical items as being from either one language or the other. The proposal hinges upon a refinement of the Abney (1987) notion of f-selection-the idea that functional heads select the features of their complements. By making the language index 
on each lexical item a feature, the FHC by Belazi et al. (1994, p. 228) states that "the language feature of the complement $\mathrm{f}$-selected by a functional head, like all other relevant features, must match the corresponding feature of the functional head". According to the model, the FHC is applied in all forms of speech-both monolingual utterances and CS. The difference, of course, is that it does not ever constrain anything in monolingual sentences as the language features always match, as the lexical items come from the same lexicon. With CS, there is a distinction in grammaticality between functional and lexical heads: a functional head and its complement must come from the same language; however, switching between a lexical head and its complement is possible. Given this, Belazi et al. (1994) cite the following as examples where switching is not allowed: between the Complementizer and the Tense Phrase, between Tense and the Verb Phrase, and between Negation and the Verb Phrase.

Using a written Acceptability Judgment Task (AJT), the target stimuli in the Toribio (2001) study of L2 CS were functional switches like those including auxiliary verbs (2a), complementizers (2b), negation (2c), and so on.

2. a. *Los estudiantes han elected a new representative.

The students have

'The students have elected a new representative.'

b. *The clinic does not treat students that $\begin{array}{lll}\text { no tienen } & \text { seguro } & \text { médico. } \\ \text { not have } & \text { insurance medical }\end{array}$

'The clinic does not treat students that don't have medical insurance.'

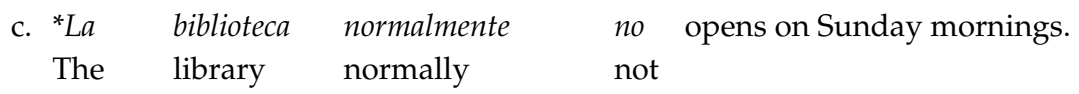

'The library normally does not open on Sunday mornings.'

The results show that proficiency of the L2 bilinguals was key for CS acceptability to align with the predictions of the FHC framework. Advanced learners were less likely to accept functional switches, whereas beginners relied on "a strategy of translation" (Toribio 2001, p. 224), and intermediate learners occupied a position somewhat in between the two. That is to say, the less proficient L2 bilinguals accepted switches where a word-for-word equivalency could be made between Spanish and the English translation, such as in (2a). It is important to note that proficiency here was determined by course level: beginners had one semester of university Spanish language study, whereas intermediate speakers had three, and advanced speakers had at least six. Overall, Toribio provides evidence that with continued linguistic development in the target language, L2 speakers can acquire the expected (un)grammaticality of intra-sentential CS.

\subsection{L2 Code-Switching and the Constraint-Free Approach}

More recently, Giancaspro (2015) conducted a similar investigation of L1-English L2-Spanish CS. Crucially different about this work is its focus on the Constraint-Free (CF) approach (MacSwan 1999, 2014) instead of the FHC. Eschewing the need of a language feature, the CF approach argues that CS grammaticality is dependent solely on features already inherent to the two grammars involved. In CS, the syntactic elements undergo feature-checking as they would in a monolingual derivation according to contemporary Minimalist syntax, following the specifications of the grammar of each element. Constraints on CS in this model are a result of movement (as a result of feature-checking) that creates a complex phonological head when mapping to the phonetic form (PF). This universal constraint is known as the PF Disjunction Theorem (MacSwan 1999). Using this analysis, the CF approach argues for a number of different reported restrictions on CS, including the ungrammaticality of auxiliary and pronoun switches, as both undergo head movement.

The switches included as stimuli in the Giancaspro (2015) study were reduced in comparison to Toribio (2001), as auxiliary switches (3a) and pronoun switches (3b) were specifically targeted. 
3. a. *They boys had pintado el cuadro.

'The boys had painted the picture.'

$\begin{array}{llll}\text { b. }{ }^{*} \text { They habian pintado el cuadro. } & \\ & \text { had } & \text { painted the picture }\end{array}$

'They had painted the picture.'

There were also three other central differences between the studies. First, Giancaspro included a 2L1 bilingual group as a direct comparison, and he had participants complete an aural AJT, instead of written. Additionally, unlike Toribio's participants, all of the L2 speakers in Giancaspro's study were enrolled in upper-level, undergraduate Spanish classes. Proficiency was instead determined using a modified version of the Diplomas de Español como Lengua Extranjera (DELE, Certificate of Spanish as a Foreign Language $)^{1}$ (Montrul and Slabakova 2003).

The results of Giancaspro (2015) show that the CS acceptability of both the L2 and 2L1 bilinguals aligned with the CF approach. Interestingly, proficiency was not found to be a relevant factor. L2 participants who scored as advanced, intermediate, and beginner all behaved similarly, rating subject-predicate switches that included a pronoun or auxiliary at the switch point consistently lower than those that did not. Recall, though, that based on the way Toribio (2001) categorized proficiency, all participants in Giancaspro's study would be considered as intermediate/advanced. In effect, the end results of both Toribio and Giancaspro's studies point in the same direction: L2 bilinguals with higher proficiency can exhibit theoretically aligned intuitions with regard to intra-sentential CS, suggesting that the developing L2 system also includes acquired linguistic knowledge related to language mixing.

\subsection{L2 Speakers' Exposure to Language Mixing}

The implications of the Toribio (2001) and Giancaspro (2015) results are particularly interesting as L2 speakers seemingly exhibit what seems to be the outcome of a "poverty of the stimulus" learning environment (Chomsky 1980, p. 34). As Toribio (2001, p.219) states, "in the context of the second language classroom [ ... ] learners receive no evidence, positive or negative, which could guide them in determining the appropriate code-switching patterns". This deviates from the typical 2L1 bilingual situation, where such a speaker is commonly exposed to language mixing from an early age. As members of a bilingual community where CS is a part of the linguistic input (in addition to monolingual utterances), it is not controversial to assume that 2L1 bilinguals "learn" to code-switch the same way they learn all other monolingual grammatical structures. ${ }^{2}$ This is not the case for L2 speakers. Unlike other grammatical structures, language mixing is not something that is ever taught (explicitly or implicitly) in an L2 classroom. In fact, its presence is almost universally frowned upon in contemporary foreign language teaching practices. A communicative approach, for example, emphasizes the benefit of maximizing the L2 and avoiding the L1, using the target language "not only [for] the planned activities, but also the classroom management that revolves around it" (Littlewood 1981, p. 45). Using the L1 results in a reduction of comprehensible L2 input, which can be considered "not an optimal condition for language acquisition to take place" (Lee and VanPatten 2003, p. 33). As a consequence, many classrooms push for almost exclusive use of the L2 by both the instructor and the

1 The DELE is an official accreditation of Spanish language proficiency given by the Instituto Cervantes on behalf of the Spanish Ministry of Education and Professional Training. For more information, see https://examenes.cervantes.es/es/dele/que-es.

2 It is worth noting that exposure to language mixing cannot be the sole factor for 2L1 bilinguals' restrictions on CS, as they can occur regardless of whether the 2L1 bilingual is a habitual code-switcher or not, and regardless of whether they live in a CS community or not. 
learners, leaving no room for CS. In such a scenario, L2 CS is understood as an intrusion of the L1 and should be avoided as much as possible. ${ }^{3}$

At the same time, we should not assume that all L2 speakers are devoid of exposure to CS. First, foreign language teachers can confirm that although classroom policies may disfavor language mixing, it is still often present. Even if the instructor conducts the class entirely in the L2, it is still common for students to move in and out of the target language, especially when communicating with each other. Also, the question of whether L2 speakers are exposed to CS should not be limited to just the classroom environment. Although a formal learning environment may be the primary source of L2 use for these speakers, it is not clear what their bilingual language behavior looks like elsewhere. The L2 could be used outside the classroom while completing coursework with fellow students, or even at social events or workplaces where other bilinguals are present.

The question remains: to what extent are L2 speakers exposed to and/or do they participate in CS? Toribio (2001) assumes not at all; however, without actually asking the participants, it is unclear if that is indeed the case. This is especially true since Giancaspro (2015) states that the majority of his L2 participants reported daily exposure to CS. Given the limited exposure to CS reported across all L2 proficiency levels, Giancaspro $(2015$, p. 402) concludes that "it seems farfetched to suggest that L2 learners could be acquiring their subtle knowledge of the particular CS points of interest on the basis of this very limited CS input". Nonetheless, L2 participants who reported having zero instances per day were not compared to those who indicated at least some exposure to it. Consequently, more detailed information regarding the role of exposure to language mixing is left unexplored.

\subsection{Research Questions and Hypotheses}

Given the aforementioned background, the following research questions are proposed in order to address the acquisition of structural restrictions on L2 CS:

1. Do L1-English L2-Spanish bilinguals accept or reject a code-switch after an auxiliary verb?

2. Do L1-English L2-Spanish bilinguals accept or reject a code-switch after a pronoun?

3. Do L1-English L2-Spanish bilinguals perform differently than 2L1 bilinguals with regard to CS judgments?

4. Does language proficiency play a role with regard to L2 CS judgments?

5. Does exposure to language mixing play a role with regard to L2 CS judgments?

Previous research (Fernández Fuertes et al. 2016; Giancaspro 2015; Toribio 2001) predicts that both auxiliary and pronoun switches should be unacceptable, and that at least a subset of L2 bilinguals will reject such switches. Similarly, bilinguals with a higher L2 proficiency will be expected to pattern with 2L1 bilinguals, as these individuals will be more likely to reject auxiliary and pronoun switches. However, it is unknown whether exposure to language mixing (or lack thereof) will have any effect on the results.

\section{Materials and Methods}

\subsection{Participants}

The primary group of participants for the current study were U.S. L1-English L2-Spanish bilinguals $(N=192)$ who learned English since birth in a natural context and then Spanish later in a school setting ( $M=11.2$ years). Recruited from third- and fourth-year university Spanish courses, their ages ranged between 18 and $33(M=20.0$ years). All participants were compensated for their time either via extra credit in their course or a small monetary amount.

3 For examples of work that challenges such a stance, see Liceras (2013, 2014); Kaushanskaya et al. (2014); Antón et al. (2015); and Avery (2015). 
The participants were first divided into groups based on reported bilingual language behavior. Specifically, they were categorized by whether or not they self-reported to be exposed to and/or participate in intra-sentential Spanish-English CS. It is not possible to simply ask a participant, "Are you a code-switcher?" as most bilinguals either do not know what that term means or have a possibly mistaken understanding of it. Instead, a series of indirect questions within the language background questionnaire was used:

1. Is there someone (or multiple people) you speak both English and Spanish with?

2. When speaking with this person (or people), do you ever use both languages in the same conversation?

3. When speaking with this person (or people), do you ever use both languages in the same sentence?

4. What is an example of something you or the other person could possibly say where both Spanish and English are used in the same sentence?

The participants fell into one of five different groups based on their respective answers. The first three questions broadly separated individuals into three categories: intra-sentential code-switchers, inter-sentential code-switchers, or neither. A participant was categorized as No CS $(n=48)$ if they answered "No" to either the first or second question, as it indicated that the person maintains complete separation between Spanish and English. Those who responded affirmatively to the first two questions but negatively to the third were categorized as Inter-sentential CS only $(n=26)$, as these individuals reported mixing their languages in conversation, but only at the sentence level. The remaining participants included the individuals who responded "Yes" to the first three questions $(n=108)$, indicating an exposure to and/or use of language mixing within the sentence (i.e., intra-sentential CS).

The participants who reported engaging in intra-sentential CS were not considered homogenous. They were further divided into three different groups based on the example mixed sentence they provided for the fourth question. Any individual who provided a response that exemplified a code-switch where the intention was purely translational and/or was due to a linguistic gap was put in a group labeled Gap intra-sentential CS $(n=30)$. Given that these participants are all L1-English L2-Spanish bilinguals, these examples included sentences where an English word or phrase was inserted into an otherwise completely Spanish sentence, explicitly due to a lack of knowing how to say it monolingually. Such examples included sentences with an actual code-switch (4a), as well as generic descriptions of such switches $(4 b, c)$.

$\begin{array}{rllll}\text { 4. a. Cómo se dice } & \text { Bachelor of Science en } & \text { español? } \\ \text { How PASS say } & & \text { in } & \text { Spanish }\end{array}$

'How do you say Bachelor of Science in Spanish?'

b. If I forget a word in Spanish.

c. When speaking Spanish and get most of the way through a sentence, then forget a word and finish in English.

Of course, it is possible that these individuals also engage in intra-sentential CS that is not merely a linguistic crutch to compensate for performance issues related to their L2 proficiency. Nonetheless, given the information provided, it is just as feasible that these individuals only switch in such circumstances, and in that case their experience with CS would be quite distinct from the type of CS that is the central focus of this investigation.

On the other hand, there were participants who were categorized as engaging in True intra-sentential CS $(n=63)$. These individuals provided an example code-switched sentence that did not involve translation and/or linguistic gaps in the L2, but rather provided mixed utterances that directly mirror those produced by 2L1 bilinguals throughout the literature (5). 
$\begin{array}{llll}\text { 5. a. I'm on my way to la clase de biología. } & \text { the class of biology }\end{array}$

'I'm on my way to biology class.'

b. A lo mejor we should go to dinner tonight.

To the better

'Maybe we should go to dinner tonight.'

Unlike the previous group, these individuals show evidence of Spanish-English mixing that is not a result of a lack of L2 proficiency. Of course, this does not rule out that these speakers do not engage in CS that is centered around a gap in their L2 linguistic competence. Nevertheless, we can assume that at least a percentage of their use of language mixing is not motivated by issues of proficiency.

The final set of participants included those considered Unclear intra-sentential CS $(n=15)$, as their example sentence could not be easily identified as either true intra-sentential CS or merely a linguistic gap in their L2. The example sentences for these individuals were always a generic explanation of when they would mix their languages but did not provide a clear enough description (6).

6. a. Talking about homework.

b. Referencing a television show.

In such situations, it is equally possible that the individual engages in either type of language mixing previously defined for the two other intra-sentential CS groups. A summary of the categorization of participants by bilingual language behavior is provided in Table 1.

Table 1. Summary of bilingual language behavior.

\begin{tabular}{|c|c|c|c|c|c|}
\hline Group & $n$ & Q1 & Q2 & Q3 & Q4 \\
\hline \multirow{2}{*}{ No CS } & \multirow{2}{*}{48} & No & - & - & - \\
\hline & & Yes & No & - & - \\
\hline Inter-sentential CS only & 26 & Yes & Yes & No & - \\
\hline Gap intra- sentential CS & 30 & Yes & Yes & Yes & $\begin{array}{l}\text { ¿Cómo se dice wallet? } \\
\text { ‘How do you say wallet?' }\end{array}$ \\
\hline True intra- sentential CS & 63 & Yes & Yes & Yes & $\begin{array}{l}\text { The printer dice que no tiene papel. } \\
\text { 'The printer says it's out of paper.' }\end{array}$ \\
\hline Unclear intra- sentential CS & 15 & Yes & Yes & Yes & We talk about cute boys in Spanish. \\
\hline
\end{tabular}

In addition to bilingual language behavior, the participants were divided into groups based on their Spanish proficiency score via the modified DELE (Montrul and Slabakova 2003). The intermediate and advanced L2 bilinguals were collapsed into the same proficiency group as there were few individuals who scored at the advanced level $(n=18)$. Therefore, participants who scored between 30 and 50 (out of 50) were considered L2 Intermediate/Advanced (Int-Adv) $(n=86)$, whereas a score between 0 and 29 was considered L2 Low $(n=96)$. The proficiency categorization combined with the aforementioned CS groupings resulted in 10 different participant groups, which are provided in Table 2. 
Table 2. Participants by bilingual language behavior and L2 proficiency.

\begin{tabular}{ccc}
\hline \multirow{2}{*}{ Group } & L2 Int-Adv & L2 Low \\
& $\boldsymbol{n}$ & $\boldsymbol{n}$ \\
\hline No CS & 22 & 26 \\
Inter-sentential CS only & 16 & 10 \\
Gap intra-sentential CS & 14 & 16 \\
True intra-sentential CS & 31 & 32 \\
Unclear intra-sentential CS & 3 & 12 \\
\hline
\end{tabular}

L2 Int-Adv: L2 Intermediate/Advanced.

Given the focus of this present study, only 4 of the 10 different groups are included in the actual data analysis. To best investigate the role of exposure to language mixing on the acquisition of L2 $\mathrm{CS}$, emphasis is placed on the two extreme ends of the spectrum: (i) those who indicate never mixing their two languages (i.e., the No CS groups); and (ii) those who indicate true intra-sentential CS (i.e., the True intra-sentential CS groups). For ease of description, these individuals will be henceforth referred to as members of the No-CS and +CS groups, respectively. Of course, as with all self-reporting on language, it must be acknowledged that participant responses are not always indicative of true behavior. Nonetheless, the process just detailed can serve as a productive approximation of the real-life distinctions in language mixing behavior among L2 bilinguals.

In addition to the L2 bilinguals, there was also a group of U.S. Spanish-English 2L1 bilinguals $(n=15)$ included as a comparison. As with the L2 participants, the 2L1 bilinguals were recruited from third- and fourth-year university Spanish courses. Commonly referred to as heritage speakers of Spanish, these individuals were exposed to Spanish since birth and English soon thereafter, by at least age 6 when entering the school system. Their ages ranged between 19 and 47 years old $(M=22.1$ years old). Unlike the L2 bilinguals, the 2L1 bilinguals all fell into the same group regarding both bilingual language behavior and Spanish proficiency. First, they engage in true intra-sentential CS (i.e., +CS), as they reported mixing Spanish and English in the same sentence and provided examples such as those in (7).
7. a. El otro día fui a Publix a comprar apples. The other day went.1sG to Publix to buy 'The other day I went to Publix to buy apples.'
b. Tenía que llamar a usted because my mom wasn't answering.
Had.1SG to call DOM you
'I had to call you because my mom wasn't answering.'

Second, they all scored above the threshold for the intermediate proficiency level of the modified DELE. An overview of the participants comparing various linguistic factors of the 2L1 and L2 bilingual groups is provided in Table 3, including the aforementioned variables, as well as parallel details regarding their English proficiency ${ }^{4}$ and their daily exposure to both languages.

Although there was no explicit measure of language dominance, all participants in this study should be considered English-dominant. This is expected for the L1-English L2-Spanish bilinguals. However, this consideration is important to note for the 2L1 bilingual group, as they were all born and raised in the U.S., with the only exception being one individual who arrived by age 1 . This presumed

4 Given the participants, a relative homogeneity with regard to English across the groups was expected. However, a proficiency measure for English was included (i) to ensure participants were actually completing the task and not just clicking through; and (ii) to reduce the stigma of only testing the proficiency level of Spanish, especially with regard to the 2L1 bilinguals, a group that often exhibits high levels of linguistic insecurity regarding their heritage language. 
English language dominance is supported by the self-rated proficiency and self-reported exposure data presented in Table 3.

Table 3. Overview of participants.

\begin{tabular}{|c|c|c|c|c|c|c|c|c|c|c|}
\hline \multirow[t]{2}{*}{ Factor } & \multicolumn{2}{|c|}{ 2L1 } & \multicolumn{2}{|c|}{$\begin{array}{c}\text { L2 } \\
+\mathrm{CS} \\
\text { Int-Adv }\end{array}$} & \multicolumn{2}{|c|}{$\begin{array}{c}\text { L2 } \\
+ \text { +CS } \\
\text { Low }\end{array}$} & \multicolumn{2}{|c|}{$\begin{array}{c}\text { L2 } \\
\text { No-CS } \\
\text { Int-Adv }\end{array}$} & \multicolumn{2}{|c|}{$\begin{array}{c}\text { L2 } \\
\text { No-CS } \\
\text { Low }\end{array}$} \\
\hline & $M$ & $S D$ & $M$ & $S D$ & $M$ & $S D$ & $M$ & $S D$ & $M$ & $S D$ \\
\hline \multicolumn{11}{|l|}{ Age of acquisition: } \\
\hline English & 3.0 & 2.5 & 0.1 & 0.4 & 0.0 & 0.0 & 0.3 & 0.9 & 0.2 & 0.9 \\
\hline Spanish & 0.3 & 1.3 & 11.5 & 3.9 & 10.8 & 3.4 & 10.3 & 3.9 & 12.1 & 3.1 \\
\hline \multicolumn{11}{|l|}{ Proficiency score: } \\
\hline English (out of 40$)^{\mathrm{i}}$ & 37.7 & 1.0 & 39.0 & 0.9 & 36.0 & 6.6 & 38.9 & 0.9 & 38.1 & 1.8 \\
\hline Spanish (out of 50) & 35.5 & 9.0 & 35.6 & 4.6 & 21.6 & 4.8 & 37.4 & 3.3 & 21.6 & 4.5 \\
\hline \multicolumn{11}{|l|}{ Self-rated proficiency: } \\
\hline English (out of 5) ${ }^{\mathrm{ii}}$ & 4.9 & 0.3 & 5.0 & 0.0 & 4.9 & 0.6 & 5.0 & 0.0 & 5.0 & 0.0 \\
\hline Spanish (out of 5) & 3.8 & 0.8 & 3.5 & 0.5 & 3.3 & 0.6 & 3.2 & 0.5 & 3.1 & 0.7 \\
\hline \multicolumn{11}{|l|}{ Self-reported exposure: } \\
\hline$\%$ English & 66.5 & 15.3 & 84.5 & 7.8 & 79.9 & 11.5 & 84.5 & 11.1 & 87.5 & 10.1 \\
\hline$\%$ Spanish & 31.9 & 15.1 & 15.3 & 7.9 & 20.1 & 11.5 & 13.3 & 8.2 & 11.5 & 7.4 \\
\hline$\%$ Other & 1.6 & 5.0 & 0.2 & 0.9 & 0.0 & 0.0 & 2.2 & 7.7 & 1.0 & 3.5 \\
\hline
\end{tabular}

${ }^{\mathrm{i}}$ The English proficiency measure was a multiple-choice cloze test $\left(\mathrm{O}^{\prime}\right.$ Neill et al. 1981). ${ }^{\text {ii }}$ The scale for self-rated proficiency was as follows: 1-Poor; 2-Needs work; 3-Good; 4-Very good; 5-Native speaker command. M: mean; SD: standard deviation.

\subsection{Task}

The task was a written AJT conducted online via Qualtrics (Qualtrics, LLC, Provo, UT, USA), in line with the general guidelines of experimental CS research proposed by González-Vilbazo et al. (2013). A written AJT was chosen over an aural AJT to align more with the methodology of other studies involving L2 CS, including Toribio (2001), Liceras et al. (2008), Fernández Fuertes et al. (2016), and Klassen (2016), albeit distancing it from that of Giancaspro (2015). Nonetheless, following Koronkiewicz and Ebert (forthcoming), both written and aural modalities of CS can provide comparable results in an AJT. The AJT was preceded by a language background questionnaire and task training, the latter of which was minimal and only included general instructions on how to complete an AJT, as well as a dozen practice sentences. Presented in code-switched Spanish-English in order to prime them for bilingual mode, the instructions highlighted avoiding prescriptive rules (i.e., lo que hayas aprendido en la escuela 'what you learned in school') and encouraged participants to focus on whether the sentence structures simply sounded "strange" or "completely fine". During the training is also when the 7-point Likert scale was introduced that explicitly asked, 'How acceptable is this sentence'/¿Qué le parece esta oración?, with the low end of the scale (i.e., 1) labeled 'Completely unacceptable'/Completamente inaceptable, and the high end (i.e., 7) labeled 'Completely acceptable'/Completamente aceptable.

Included in the AJT were Spanish-English code-switched sentences $(n=54)$, as well as monolingual blocks of Spanish $(n=27)$ and English $(n=27)$. A complete list of all experimental stimuli is included in Appendix A. The experimental blocks were separated by the proficiency measures, so that the overall order of the experiment was as follows: background questionnaire; training; CS AJT block; Spanish proficiency measure; monolingual Spanish AJT block; English proficiency measure; monolingual English AJT block. Within the blocks, all stimuli were individually randomized for each participant.

\subsection{Stimuli}

The target stimuli focused on two different types of switches, which I refer to generally as (i) "verb switches" $(n=12)$, and (ii) "subject switches" $(n=12)$. For the former, the critical difference is whether the language switch occurs after a finite auxiliary verb $(n=6)$ or before a finite lexical verb $(n=6)$; 
whereas for the latter, the switch occurs after either a pronominal subject $(n=6)$ or a lexical DP subject $(n=6)$. The code-switched stimuli were half Spanish-to-English switches, and half English-to-Spanish switches. Examples of the verb switches are in (8), and examples of the subject switches are in (9).
8. a. *Su hermano ha trained at the gym every day.
His brother has
'His brother has trained at the gym every day.'
b. *Su hermano trains at the gym regularly.
his brother
'His brother trains at the gym regularly.'
9. a. ${ }^{*} \mathrm{He}$ pidió una cerveza.
ordered a Beer

'He ordered a beer.'
b. *That guy pidió un vaso de agua.
'That guy ordered a glass of water.'

In (8) we see an example of the verb stimuli for Spanish-to-English switches. First, there is the expectedly unacceptable switch (8a) as shown with the Spanish auxiliary verb haber 'to have' and an English finite participle, in this case trained. The companion control stimulus (8b) includes no auxiliary, but rather switches between the Spanish lexical DP in subject position, in this case su hermano 'his brother', and the finite lexical verb in English, in this case trains. In (9), we see the same for the pronoun stimuli. Here, the expectedly unacceptable switch (9a) includes an English weak pronoun, in this case $h e$, and a finite lexical verb in Spanish, in this case pidió 'ordered'. The respective control stimulus (9b) includes an English full lexical DP, here that guy, switched with the same Spanish finite verb.

Note that for both the verb and subject switches, the comparison control switch is the exact same type of sentence: a lexical DP switched with a finite verb (with no auxiliary), as shown in (8b) and (9b). These stimuli are included as a baseline comparison of CS acceptability. Since a lexical DP switched with a finite verb is one of the most commonly cited switches in the literature, the ratings of these stimuli should provide an understanding of where on the Likert scale the participants consider a switch as completely acceptable. Consequently, if the auxiliary switches and/or pronoun switches are rated significantly lower, we know that the participants consider such a switch (at least to some extent) unacceptable. Without this comparison, the first two research questions would not be answerable without drawing an arbitrary line on the Likert scale where "acceptable" ends and "unacceptable" begins. Given that these control stimuli have the same sentence structure, an alternate option would have been to include just one set of lexical DP switches. However, two different sets of comparison stimuli were tested as the auxiliary switches and pronoun switches were designed using distinct lexical verbs. By having two sets of lexical DP switches, the auxiliary switches and pronoun switches can be directly compared to acceptable switches with similar lexical material.

All target stimuli followed the same basic structures shown in (8) and (9). The subject was always third person, half the time singular and half plural, balanced across conditions. Similarly, gender of the subject was explicitly feminine half of the time, with the other half being masculine. All lexical DPs in subject position included solely a distal demonstrative (e.g., that, those) or a possessive adjective (e.g., his, their) in the same language as the noun phrase. Following the verb was always either an adverbial adjunct or direct object complement in the same language as the finite verb, except in the case of the verb switches where these sentence-final elements were in the same language as the participle. The verb switches always included the present perfect, which meant a form of either have in English or haber 'to have' in Spanish. 
Also included were monolingual comparisons for both the verb stimuli $(n=12)$ and subject stimuli $(n=12)$. These sentences were equivalent to their code-switched counterparts except for the crucial difference of being entirely monolingual. Monolingual English examples of the verb stimuli are in (10), and similar examples of the subject stimuli are in (11).

10. a. Her brother has trained at the gym every day.

b. Her brother trains at the gym regularly.

11. a. He ordered a beer.

b. That guy ordered a glass of water.

The remaining stimuli were different filler sentences. For the code-switched block, the filler stimuli $(n=30)$ included complex sentence switches, coordinated pronoun switches, direct object switches, present progressive switches, and other general subject-predicate switches. The monolingual English fillers $(n=15)$ and monolingual Spanish fillers $(n=15)$ included the same structures just mentioned, as well as unacceptable that-trace violations and adjective violations for English, and unacceptable negation violations and adverb violations for Spanish.

\section{Results}

\subsection{Verb Switches}

Before analyzing the CS results, it is important to first assess the ratings received for the monolingual stimuli. Following Ebert and Koronkiewicz (2018), monolingual judgments can provide a benchmark comparison of acceptability, as well as point out any potential ungrammaticality that stems from elements unrelated to CS. That is, if participants rate a monolingual sentence as unacceptable, rating that same sentence as unacceptable when code-switched tells us nothing interesting about the grammaticality of the switch. However, if the opposite is true, where participants rate a monolingual sentence as completely acceptable, but the code-switched version as unacceptable, we can be assured that the difference is due to the switch and the switch alone.

The results for the monolingual verb stimuli are presented in Figures 1 and 2..$^{5}$ Overall, we can see that all the participants favored both types of verb stimuli, providing mean ratings at the high end of the acceptability scale. This is not surprising, given that these are all grammatical sentences in both Spanish and English. This was confirmed by a two-way ANOVA of all the monolingual verb stimuli that examined the effect of group and stimulus type (i.e., Aux $+\mathrm{V}$ or V-only) on rating. A main effect was found for both group, $F(4,1562)=14.442, p<0.001$, and type, $F(1,1562)=33.836, p<0.001$, but there was no significant interaction, $F(4,1562)=0.613, p=0.653$. A Tukey post hoc analysis revealed that the 2L1 bilingual group rated everything significantly lower than all other groups, $p<0.0001$, but no other significant group differences were found. This tells us that, in spite of the trend of high acceptability extended throughout all participant groups, the 2L1 bilinguals rated everything just slightly lower than the other groups. Also, in the monolingual English condition, the stimuli that included just a regular finite verb (V-only), received slightly higher scores than the stimuli that included an auxiliary verb and a participle $(\mathrm{Aux}+\mathrm{V})$ instead. Why these differences were found with the monolingual stimuli will be addressed in more detail in Section 5.4.

5 The error bars in all of the figures represent the standard error for each respective mean rating. 


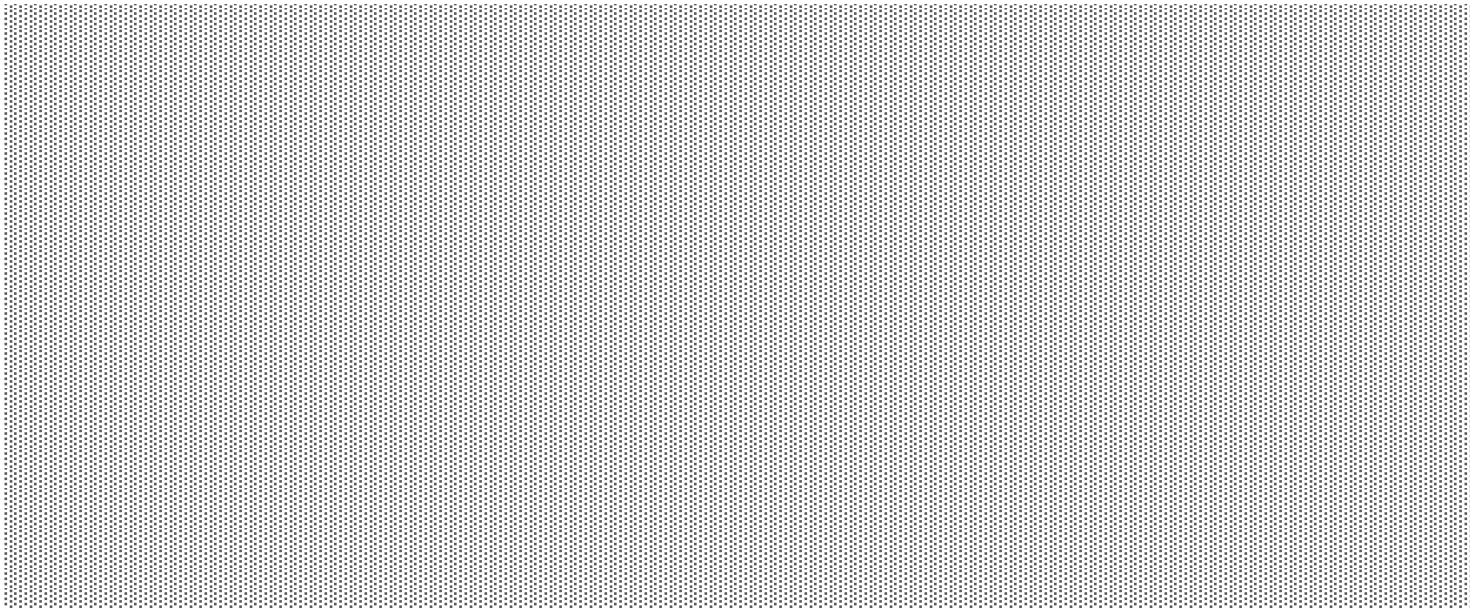

Figure 1. Monolingual English verb stimuli ratings by group and type. Aux $+\mathrm{V}$ : auxiliary verb and participle; V-only: regular finite verb; Int-Adv: Intermediate/Advanced; +CS: true intra-sentential code-switching groups; No-CS: non-code-switching groups.

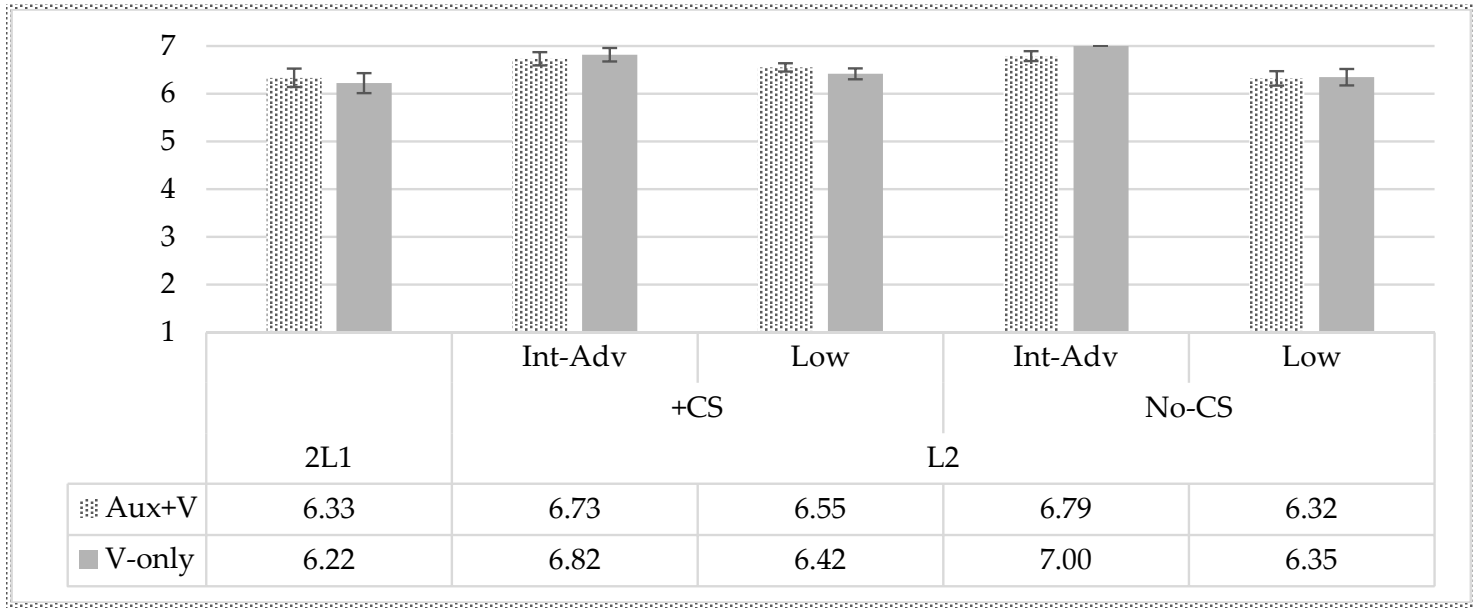

Figure 2. Monolingual Spanish verb stimuli ratings by group and type.

We can now turn to the code-switched verb stimuli. The combined CS results are presented in Figure 3, with them separated by switch direction (i.e., English-to-Spanish or Spanish-to-English) in Figures 4 and 5. Here we see a different picture than with the monolingual stimuli. The control V-only stimuli, which included just a lexical DP switched with a finite verb, received favorable acceptability scores, with judgments toward the high end of the scale, just like their monolingual counterparts. The Aux $+\mathrm{V}$ stimuli, however, received much lower scores, more toward the middle of the scale. This pattern follows expectations, as such a switch is said to be ungrammatical following the theoretical framework and previous research, whereas the control switch is not. In short, there is an overall tendency across the groups so that the less a bilingual uses CS and the less proficient they are, the higher the rating of the unacceptable auxiliary switch. There is some minor variability when comparing the switch direction, as the L2 +CS Low group and both L2 No-CS groups found a larger distinction in acceptability when the switch was from Spanish-to-English; however, the overall trend is consistent. 


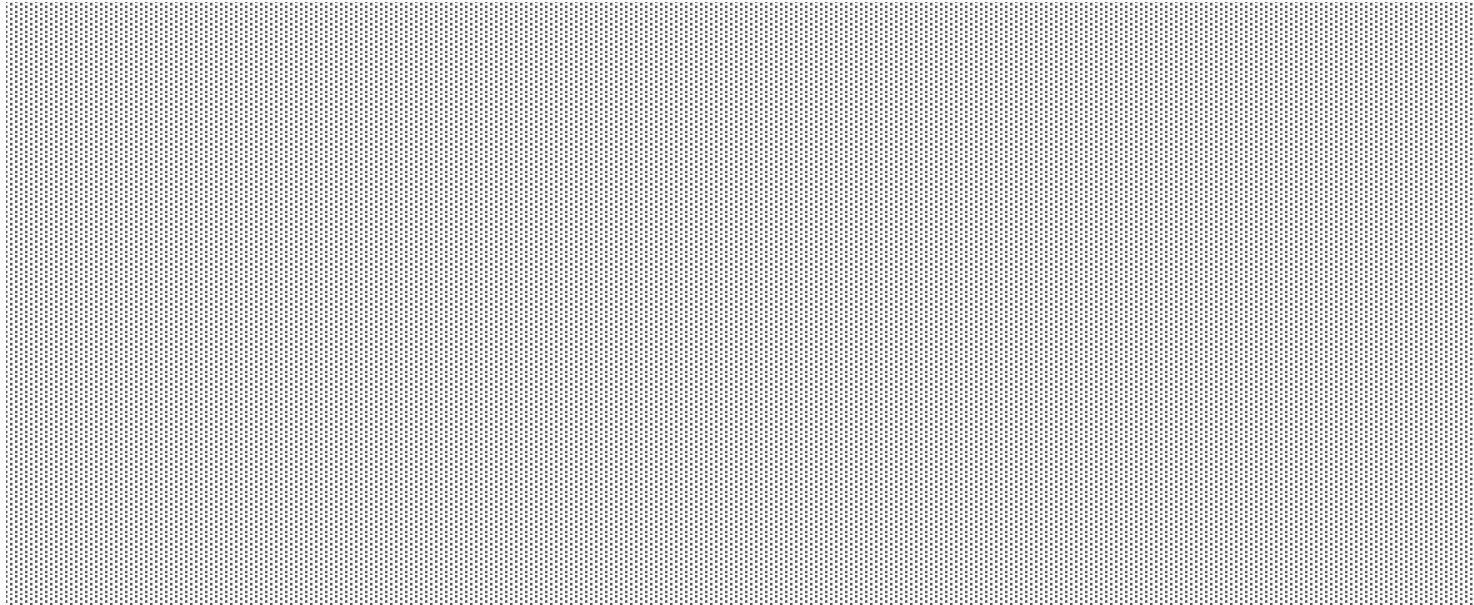

Figure 3. Code-switched verb stimuli ratings by group and type.

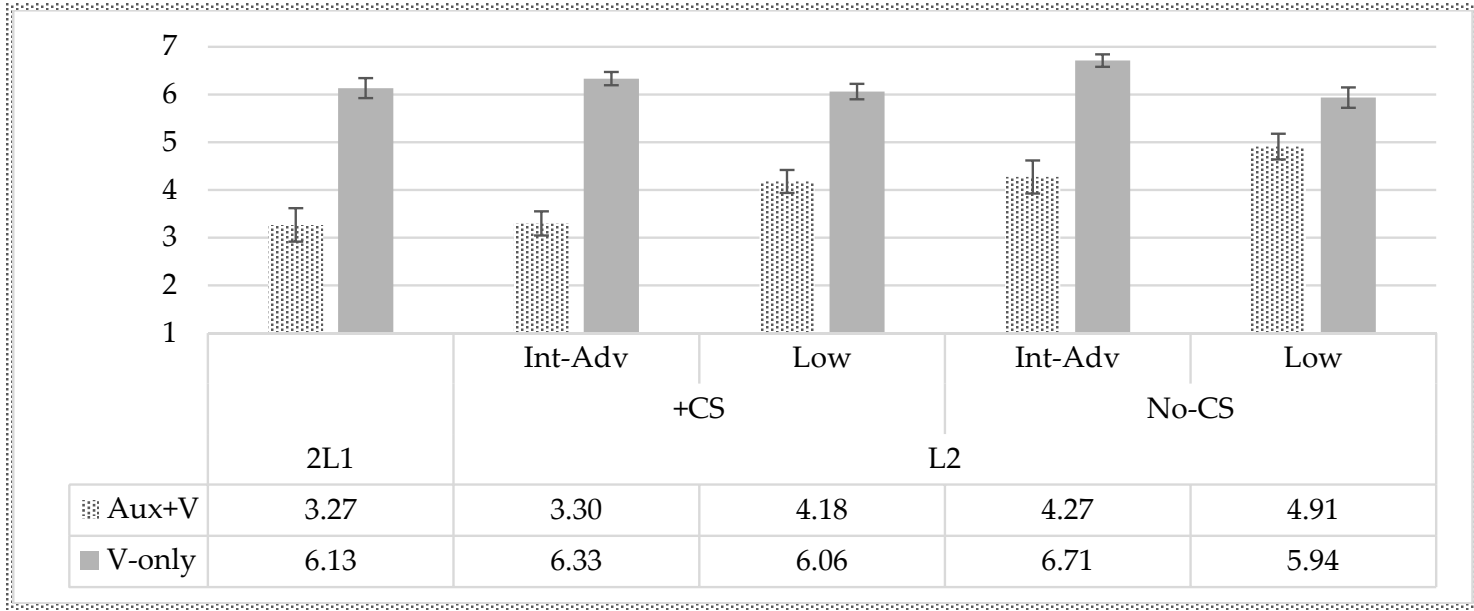

Figure 4. Code-switched English-to-Spanish verb stimuli ratings by group and type.

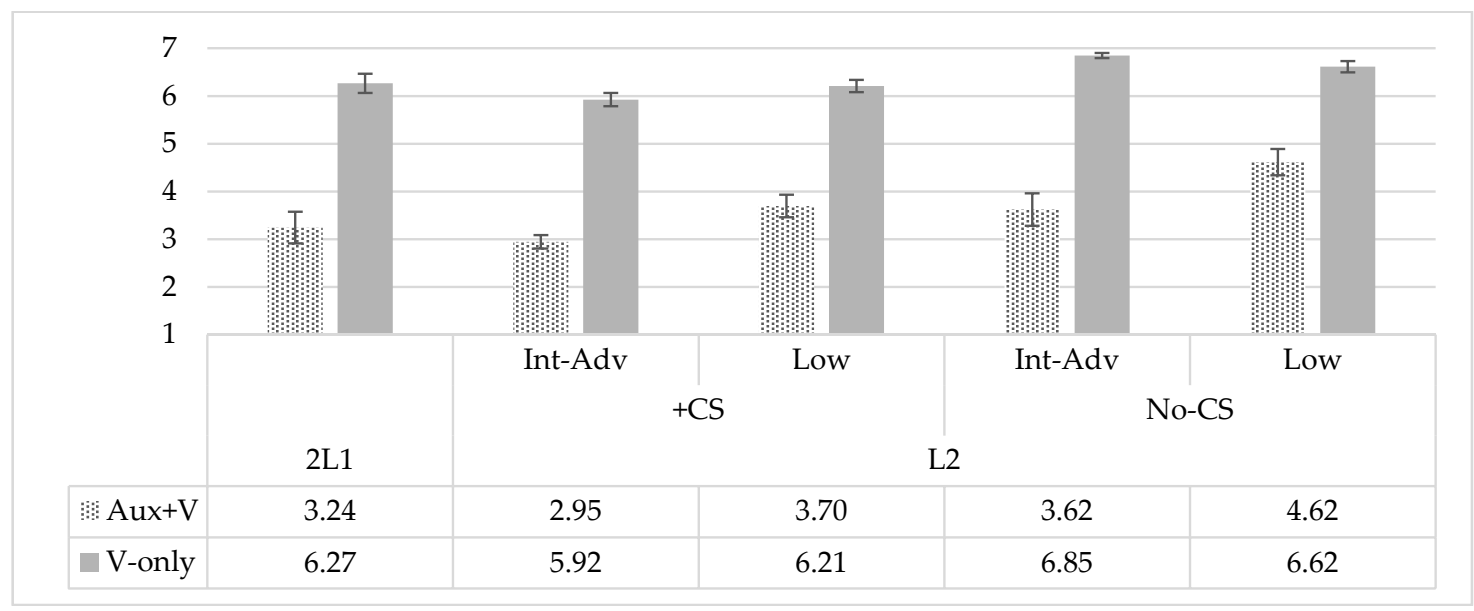

Figure 5. Code-switched Spanish-to-English verb stimuli ratings by group and type.

A two-way ANOVA measuring the effect of group and stimulus type on rating revealed a main effect for both group, $F(4,1562)=54.001, p<0.001$, and type, $F(1,1562)=537.089, p<0.001$, as well as a significant interaction between the two, $F(4,1562)=6.898, p<0.001$. Post hoc analysis using a Bonferroni correction for multiple comparisons indicated that all groups rated the Aux $+\mathrm{V}$ switches 
significantly lower than the V-only switches, $p<0.001$. As for the amount of distinction made between the two switch types, the differences in mean ratings for the 2L1 the L2 +CS Int-Adv groups were found to be significantly larger than all other groups, $p<0.05$, but not each other. Additionally, the L2 + CS Low group made a distinction that was significantly larger than the L2 No-CS Low group, $p<0.05$. No other significant differences between groups were found.

\subsection{Subject Switches}

We must again assess the ratings received for the monolingual stimuli first to ensure the (un)acceptability found in CS results is specific to the language switch. The results for the monolingual subject stimuli are presented in Figures 6 and 7. A two-way ANOVA of all the monolingual subject stimuli measuring the effect of group and stimulus type (i.e., weak pronoun or lexical DP) on rating found a main effect for group, $F(4,1562)=18.690, p<0.001$, but not type, $F(1,1562)=3.581, p=0.059$. A Tukey post hoc analysis revealed that the $2 \mathrm{~L} 1$ bilingual group and the L2 $+\mathrm{CS}$ Low group were found to rate all stimuli lower than the other three groups, $p<0.05$, but not each other. No other significant differences were found.

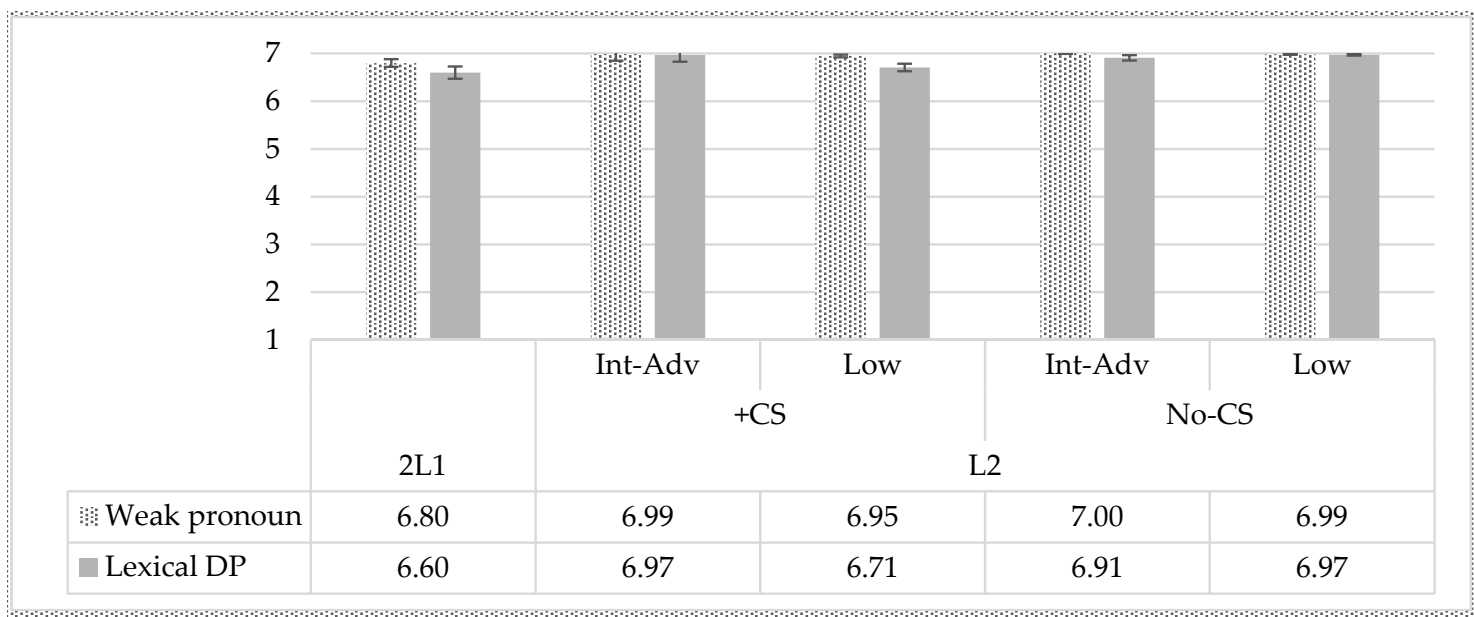

Figure 6. Monolingual English subject stimuli ratings by group and type. DP: determiner phrase.

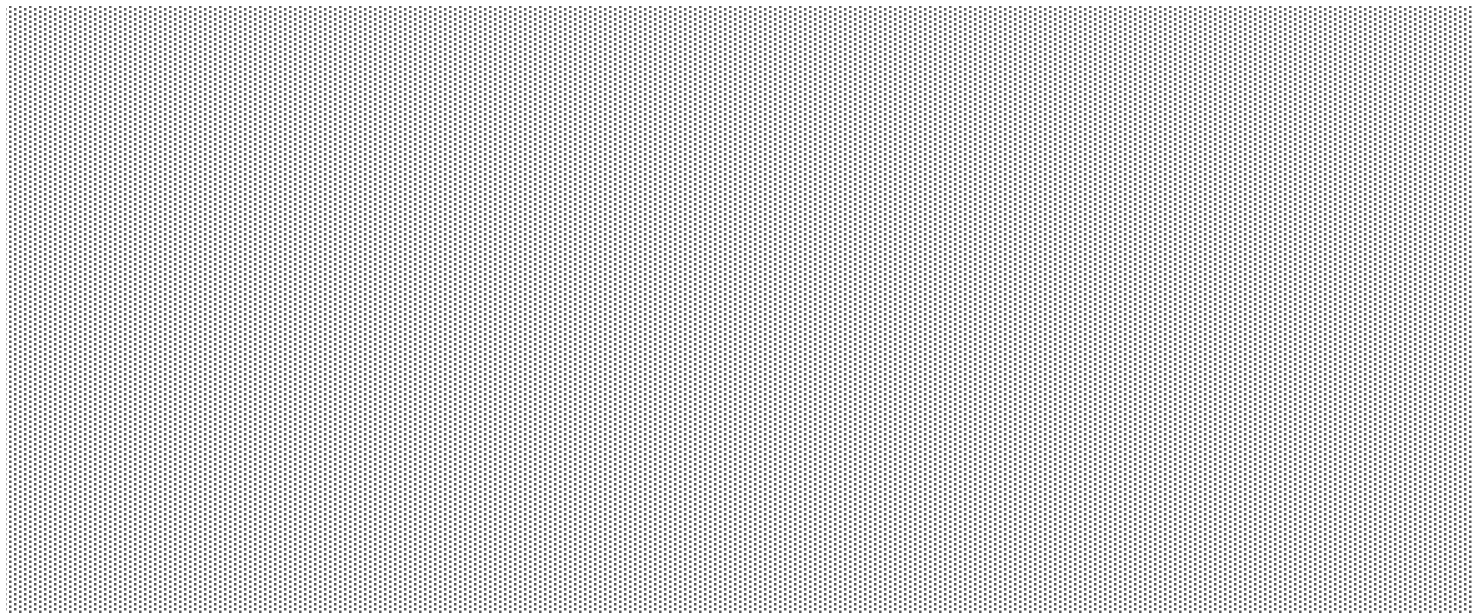

Figure 7. Monolingual Spanish subject stimuli ratings by group and type.

The combined code-switched subject stimuli are presented in Figure 8, with the results separated by switch direction (i.e., English-to-Spanish or Spanish-to-English) in Figures 9 and 10. As was the case with the verb stimuli, we see a clear distinction between the code-switched subject stimuli and their 
monolingual comparisons. Although the control lexical DP stimuli received favorable scores at the high end of the acceptability scale, the weak pronoun stimuli ratings are reduced and more variable, including some scores averaging toward the middle of the scale. Even more interesting, though, is that the weak pronoun stimuli ratings seem to vary more substantially from group to group, with the 2L1 bilingual group rating them the lowest, and the L2 No-CS Low group rating them at almost the same level as the lexical DP stimuli. Again, there is some minor variability when comparing the switch direction, as the Spanish-to-English switches seem to be rated as slightly more acceptable across the board. Nonetheless, the overall trend remains the same: the less a bilingual uses CS and the less proficient they are, the higher the rating of the unacceptable switch, which in this case included a pronoun.

A two-way ANOVA measuring the effect of group and stimulus type on rating revealed a main effect for both group, $F(4,1562)=21.162, p<0.001$, and type, $F(1,1562)=112.515, p<0.001$, as well as a significant interaction between the two, $F(4,1562)=11.585, p<0.001$. Post hoc analysis using a Bonferroni correction for multiple comparisons indicated that all groups except the L2 No-CS Low group rated the weak pronoun switches lower than the lexical DP switches, $p<0.05$. As for the amount of distinction made between the two switch types, the difference in mean ratings for the 2L1 bilingual group was found to be statistically larger than all other groups, $p<0.001$. Additionally, the L $2+\mathrm{CS}$ Int-Adv group made a distinction that was found to be significantly larger than both No-CS groups, $p$ $<0.05$, as was the case for the L2 +CS Low group and the L2 No-CS Int-Adv group, $p<0.05$. No other significant differences between groups were found.

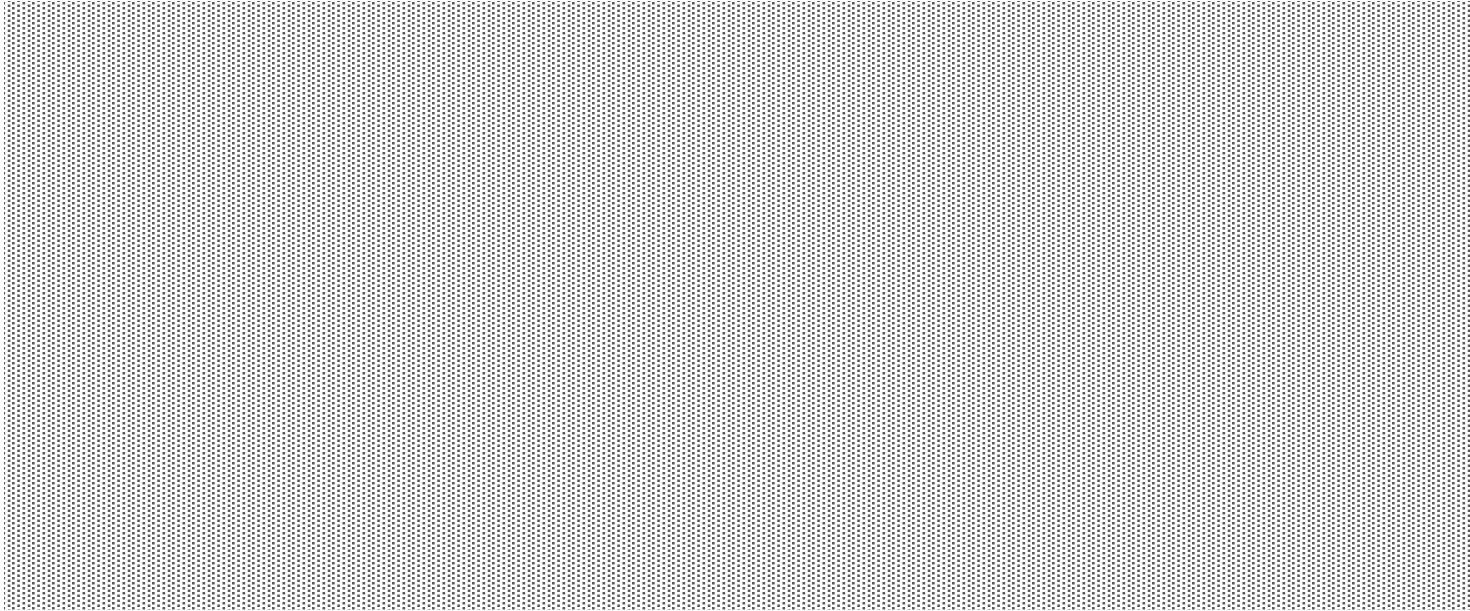

Figure 8. Code-switched subject stimuli ratings by group and type.

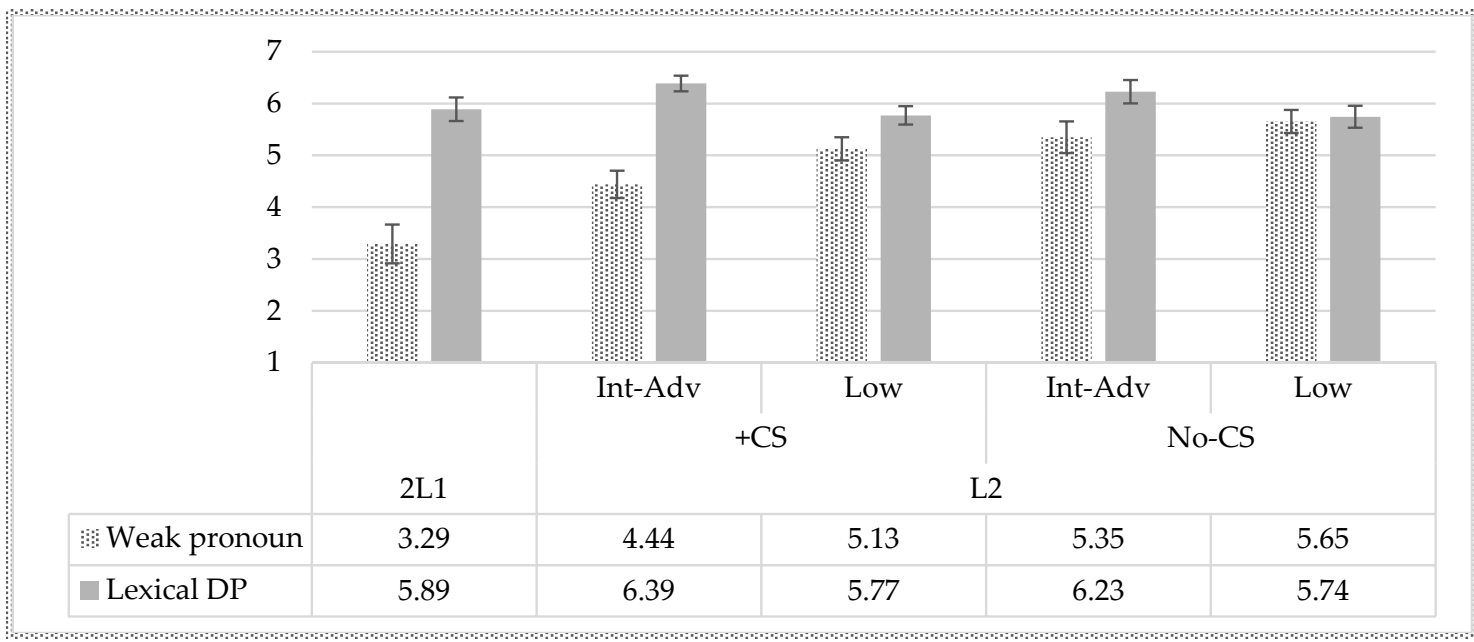

Figure 9. Code-switched English-to-Spanish subject stimuli ratings by group and type. 


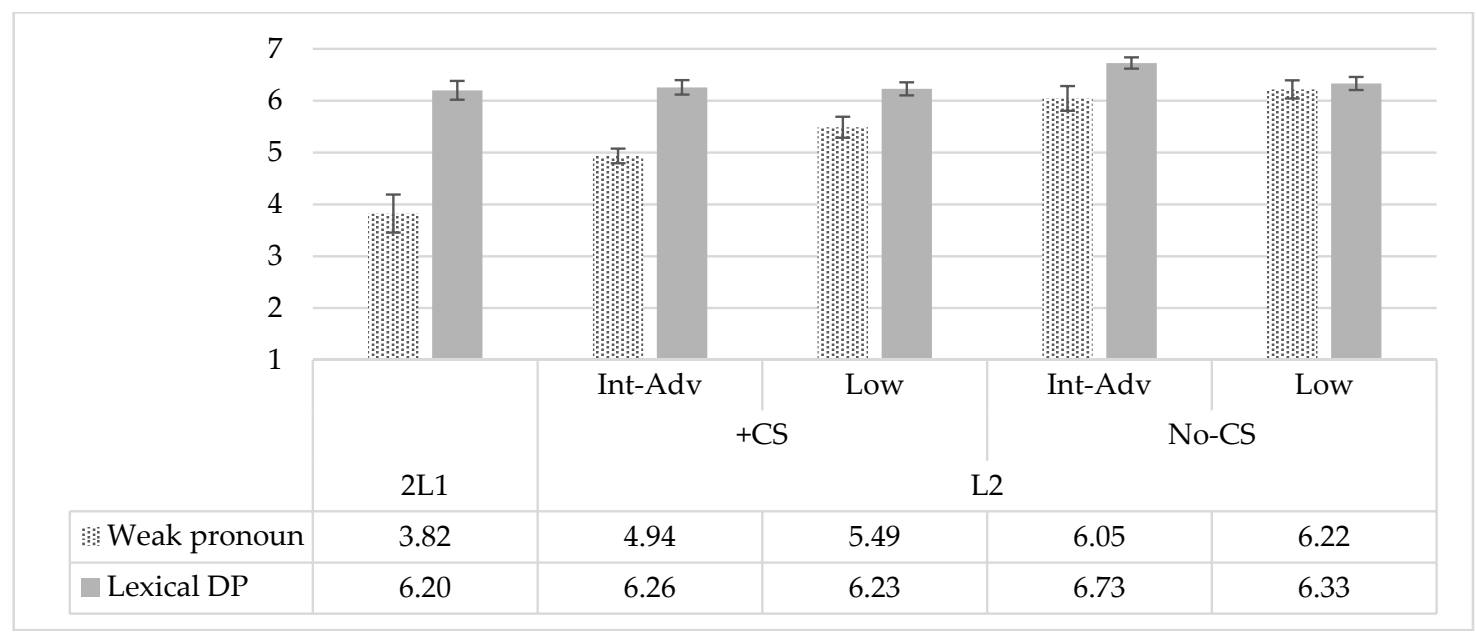

Figure 10. Code-switched Spanish-to-English subject stimuli ratings by group and type.

\section{Discussion}

\subsection{Differences between Switch Types}

There was an almost-universal trend in which participants showed the expected pattern of CS (un)acceptability. This was evidenced by all groups judging a switch between an auxiliary verb and a participle less acceptable than a standard subject-predicate switch. In other words, the reduced acceptability of an auxiliary switch exhibited itself regardless of bilingual type, Spanish proficiency, or bilingual language behavior. These findings are intriguing in that they suggest that without exposure to and/or production of CS, L2 bilinguals even at a lower proficiency level show evidence of linguistic competence regarding constraints on intra-sentential CS. At a broad level, this finding is in line with the Giancaspro $(2015)$ study, as it supports the proposal by MacSwan $(1999,2014)$ that there are no constraints on CS except for the features of the two grammars in question. Although we have no way of knowing what cognitive strategies were employed during the task, given the surface-level similarity between Spanish and English auxiliary structures, it at least suggests that participants were not simply relying on word-for-word translation (e.g., being able to simply substitute a Spanish auxiliary for an English one, or vice versa), as we would not have seen a result where the Aux $+\mathrm{V}$ stimuli were consistently rated lower than the V-only comparison stimuli.

Nevertheless, although the expected patterns of CS (un)acceptability were pervasive in the results, they were not absolute. By turning to the subject stimuli results, we have a more nuanced picture, showing that the particular structure under analysis is relevant, highlighting the importance of not collapsing switch types into too-broad categories. Unlike with the verb stimuli, with the subject stimuli, the participant groups did not all differentiate between the expectedly unacceptable stimuli and the control stimuli. The L2 No-CS Low group diverged by finding pronoun switches just as acceptable as lexical DP switches. This finding in combination with the auxiliary switch results tells us that the acquisition of the constraints on CS is not all or nothing. That is to say, it suggests that the same way L2 speakers acquire different features of the L2 in stages, so too do they acquire different CS restrictions. Based on the current results, it seems the restriction on auxiliary switches is acquired earlier than that on pronoun switches. The fact that auxiliary switches are much more salient than pronoun switches could be a possible explanation for this distinction. Using Ravid's (1995, as cited in Gass et al. 2017, p.117) definition of salience as "the property of a structure that is perceptually distinct from its environment", the fact that the auxiliary construction includes both the finite verb and the participle makes it stand out as opposed to the more straightforward subject switches. 


\subsection{Differences Between Groups}

Despite this overall trend of L2 bilinguals exhibiting expected distinctions in CS acceptability, it is important to note that the degree of the distinction varied among the different groups. Although most L2 participants demonstrated that they differentiate between the expectedly unacceptable switches and the control switches, the groups' average ratings were not identical for the different switch types. Using the 2L1 bilingual group's ratings as a comparison, we can analyze the extent of the distinction between the expectedly unacceptable and control switches to tap into how their L2 linguistic systems are developing with regard to CS. When rating code-switched verb sentences, for example, the L2 + CS Int-Adv group and the 2L1 bilinguals formed one cohesive unit. In other words, for these switches, the L2 +CS Int-Adv group performed entirely 2L1-like, exhibiting strong intuitions about the ungrammaticality of an auxiliary switch. Meanwhile, the remaining groups formed a hierarchy with regard to this same distinction. The +CS Low made more of a distinction than the No-CS Low group, and the No-CS Int-Adv occupied an intermediary position between the other two groups. We can interpret this to mean that both proficiency and bilingual language behavior play a role in the acquisition of L2 CS constraints regarding verb switches.

The story is slightly different for the subject stimuli. Unlike with the verb stimuli, no L2 participants exhibited judgments that mirrored the 2L1 bilingual group, which made a much larger distinction between pronoun and lexical DP switches than all other groups. Nonetheless, both bilingual language behavior and proficiency again seem to be playing a role. The results suggest that the constraint on pronoun switching can be acquired by either (i) increased proficiency in the L2 or (ii) exposure to language mixing, as evidenced by both the L2 +CS Low and L2 No-CS Int-Adv group ratings. Importantly, though, the group with the most 2L1-like judgments (i.e., the highest distinction between the switch types) was the L2 +CS Int-Adv group. This suggests that although these L2 bilinguals are not patterning exactly like the 2L1 bilinguals as they were with the verb stimuli, more nuanced competence in L2 CS restrictions occurs with a combination of both higher proficiency and exposure to language mixing.

\subsection{Limitations}

There are certain limiting factors, both in the methods and analysis, that are worth discussion. First, recall the comparison structure for the auxiliary switches, as originally shown in (8b). These control stimuli do not include an auxiliary verb, although the lexical material is otherwise equivalent. A more direct comparison is possible if the control stimuli explicitly included an auxiliary, but without involving it in the actual switch. This could include having the switch occur after the participle (12a) or before the auxiliary (12b).

12. a. Su hermano ha entrenado at the gym every day.
His brother has trained

'His brother has trained at the gym every day.'

b. Su hermano has trained at the gym every day.

His brother

'His brother has trained at the gym every day.'

The type of switch shown in (12a) was the comparison Toribio (2001) included, whereas the one in (12b) was used by Giancaspro (2015). As the current study only has data for a nonauxiliary comparison, it is unknown if the results would be altered by using a comparison like (12a) or (12b). It is possible that the degree of the distinction found between the two types of verb switches would be reduced, as the control stimuli in (12) might not produce the same high level of acceptability as the one in (8b). Nevertheless, as the switches in (8b) and (12) are all considered acceptable throughout the literature, one could expect that the overall trend in the results would remain unchanged. 
It is also worth noting again that language dominance was not explicitly measured. As Liceras et al. (2008) and Liceras et al. (2016) have demonstrated, language dominance is a strong predictor of CS preferences. Importantly, all participants in the current study are assumedly English-dominant, so any dominance effect should be comparable for both the 2L1 and L2 bilingual groups. Nonetheless, it was not actively controlled for, and as such it may be having an unseen influence, particularly within the 2L1 bilingual group.

Finally, the analysis of the results did not focus heavily on the switch direction (i.e., English-toSpanish or Spanish-to-English). Although the descriptive results are provided, the statistical analyses collapse the code-switched stimuli into one category. This was done to align directly with the analyses of Toribio (2001) and Giancaspro (2015). Albeit beyond the scope of the current paper, it is possible to employ a more fine-tuned analysis regarding how these types of switches may vary depending on whether the auxiliary or pronoun is in English or Spanish. As noted descriptively, there was some minor variation in the results. First, although the $2 \mathrm{~L} 1$ bilinguals and the L2 +CS Int-Adv bilinguals did not seem to differentiate between switch direction for the verb stimuli, the other three groups did seem to slightly disfavor a Spanish auxiliary switched with an English participle compared to the other way around. As for the subject stimuli, there seemed to be no group variation. However, Spanish-to-English switches did seem to be slightly more favored, regardless of whether the subject was a pronoun or a lexical DP. Crucially, though, these issues do not have an obvious impact on the overall trend in which both increased exposure to language mixing and higher proficiency in Spanish result in larger distinctions in (un)grammaticality for both switch types.

\subsection{Future Directions and Final Thoughts}

Overall, the results are in line with both Toribio (2001) and Giancaspro (2015): L1-English L2-Spanish bilinguals are able to acquire the expected restrictions on CS. Additionally, the findings regarding proficiency are compatible with previous research. First, although Toribio did find differences based on proficiency level, recall that the low-level L2 speakers in her study were those with only one semester of university-level Spanish study. Like Giancaspro, the participants of the current study had multiple semesters of study, so it is not surprising that the majority of L2 speakers made distinctions within their CS judgments. Moving beyond proficiency, the new results show how looking at proficiency is not sufficient, as exposure to language mixing can play just as crucial a role in L2 bilinguals acquiring constraints on CS.

Although insightful, the current results should be considered just a first step in understanding the role of bilingual language behavior with regard to L2 CS. Future work is needed to investigate more fine-tuned aspects of exposure to language mixing. For example, the current analysis does not address the level of exposure to language mixing. Participants were divided into categorical groups of exposure to CS or not; however, it is possible that even within the +CS group, more detailed differences could be found. It is not unreasonable to assume that increased frequency in exposure to language mixing would produce more differentiation between the switch types. Furthermore, there are a multitude of more specific questions about exposure to language mixing. Are these L2 bilinguals mostly receiving CS in their input, or are they also producing it? Who are the interlocutors involved in these interactions-other L2 bilinguals or 2L1 bilinguals? When and where are these mixed languages interactions occurring? These questions, among others, could help paint a much clearer picture of how L2 bilinguals end up acquiring constraints on CS.

Having addressed the importance of the CS findings, recall we did find some differences in the monolingual stimuli as well. First, why were the monolingual Aux $+\mathrm{V}$ stimuli rated significantly lower than the monolingual V-only comparison? This is possibly an artifact of the particular English lexical choices, particularly with regard to the varied adjunct Adverbial Phrases (i.e., every day, at the elementary school, recently). Given the complexity of the tense-aspect requirements of the present perfect, a more controlled stimuli design could alleviate this issue. Importantly, though, the ratings for the monolingual Aux $+\mathrm{V}$ sentences were still substantially higher than for the code-switched Aux $+\mathrm{V}$ 
sentences, indicating that the switch itself does indeed have an effect on acceptability. Second, why is it that the 2L1 group patterned differently? Note that the 2L1 bilingual participants provided depressed ratings throughout the entire study, for both monolingual and CS judgments. When looking at the CS stimuli ratings, we see that the control switches are not receiving scores at ceiling, just like the monolingual ratings. For whatever reason, this particular group was more critical of all structures, and was therefore reticent to give any structure a "perfect" score of acceptability. Interestingly, though, the L2 bilingual groups were perfectly fine with using the full scale for the monolingual stimuli. But, when judging the CS stimuli, we see a reduction in acceptability across the board. This could be indicative of some inherent bias against CS as a stigmatized form of communication (Bullock and Toribio 2009; Montes-Alcalá 2001; Poplack 1980; among others). This is in line with Badiola et al. (2018), who report that a negative perception of CS results in lower ratings in an AJT. As for the difference between the 2L1 and L2 groups, it is known that different groups of speakers can have variable biases, such as Liceras et al. (2008) finding that L1 French speakers rated code-switched structures consistently lower than L1 English or L1 Spanish speakers. What is interesting, though, is that many of the current study's L2 participants were still able to distinguish between the switch types, even though they did not consider the acceptable forms as acceptable as monolingual sentences.

Finally, we can return to the poverty of the stimulus argument for L2 CS. The results of the current study help illuminate two important factors in this regard. First, contrary to what Toribio (2001) suggests, the current study further dispels the notion that L2 speakers are not exposed to CS, as at least a subsection of them report experiencing some level of language mixing. We cannot assume that all L2 bilinguals exhibit an almost idealized poverty of the stimulus for learning CS constraints. As evidenced here, there are at least some L2 speakers who report engaging in true intra-sentential CS. However, secondly, this finding should not be taken as evidence against the poverty of the stimulus argument. The participants that best represent a poverty of the stimulus are those in the No-CS groups, as they are specifically defined by a lack of exposure to language mixing. Recall that these groups were able to show expected patterns of (un)acceptability in code-switched sentences, unanimously in the case of the verb switches, and those with higher proficiency for the subject switches. That is to say, with individuals who report lacking CS input, we have evidence that the constraints on CS can still be acquired. This again follows MacSwan's $(1999,2014)$ proposal where there are no restrictions specific to CS; each bilingual is able to switch (or not) depending on the features they already have available from their two grammars. As such, these findings for the No-CS groups support the poverty of the stimulus argument. Nonetheless, the current study suggests that, although acquisition without exposure to CS is possible, both increased proficiency and exposure to language mixing maximize this acquisition.

Funding: This research received no external funding.

Acknowledgments: The author would like to thank Rolf Tilley for his assistance in preparing the experimental materials. The author would also like to thank Rafael Álvarez, Alicia Cipria, Mandy Faretta-Stutenberg, Xabi Granja, Jessica Hubickey, Connie Janiga-Perkins, Ernesto Kortright, Marie-Eve Monette, Erin O'Rourke, Ali Perkins, Shirin Posner, Iñaki Rodeño, Laura Rojas-Arce, and Ana Skelton for their help in recruiting participants. Further thanks are extended to the audience members of the University of Tennessee at Knoxville 2017 Spring Linguistics Symposium and the 2017 Hispanic Linguistics Symposium for their feedback on previous versions of this paper.

Conflicts of Interest: The author declares no conflict of interest.

\section{Appendix A}

Code-Switched Auxiliary Stimuli

Su hermano ha trained at the gym every day.

Su hermano trains at the gym regularly.

The students have prestado atención a la profesora hoy.

The students prestan atención a la profesora en clase. 
Nuestra tía ha taught fourth grade at the elementary school.

Nuestra tía teaches psychology at the community college.

Her colleagues have visto muchas películas this year.

Her colleagues ven muchas películas en el cine.

Sus amigas han gone shopping with their mothers recently.

Sus amigas go shopping with their mothers frequently.

Your neighbors have comido en ese restaurante varias veces.

Your neighbors comen en ese restaurante todas las semanas.

Monolingual English Auxiliary Stimuli

His brother has trained at the gym every day.

His brother trains at the gym regularly.

Our aunt has taught fourth grade at the elementary school.

Our aunt teaches psychology at the community college.

Her friends have gone shopping with their mothers recently.

Her friends go shopping with their mothers frequently.

Monolingual Spanish Auxiliary Stimuli

Los estudiantes han prestado atención a la profesora hoy.

Los estudiantes prestan atención a la profesora en clase.

Sus colegas han visto muchas películas este año.

Sus colegas ven muchas películas en el cine.

Tus vecinos han comido en ese restaurante varias veces.

Tus vecinos comen en ese restaurante todas las semanas.

Code-Switched Pronoun Stimuli

Él met our grandmother.

Ese chico met our cousin.

He pidió una cerveza.

That guy pidió un vaso de agua.

Ellos bought some peaches.

Esos hombres bought some apples.

They compraron unas manzanas.

Those guys compraron unos duraznos.

Ellas started to sing.

Esas chicas started to dance.

She conoció a nuestro primo.

That girl conoció a nuestra abuela.

Monolingual English Pronoun Stimuli

He ordered a beer.

That guy ordered a glass of water.

They bought some apples.

Those guys bought some peaches.

She met our cousin.

That girl met our grandma. 
Monolingual Spanish Pronoun Stimuli

Él conoció a nuestra abuela.

Ese chico conoció a nuestro primo.

Ellos compraron unos duraznos.

Esos hombres compraron unas manzanas.

Ellas empezaron a cantar.

Esas chicas empezaron a bailar.

Filler Code-Switched Stimuli

Todos van a mojarse if it rains today.

Ella se esconde when he calls her.

Voy a salir if I feel sick.

Sometimes he'll go to the store y olvida lo que estaba buscando.

We'll hear a sound si alguien toca el timbre.

We'll tell him si lo vemos.

Casi nadie visits the museum.

Ninguna persona aquí has a knife.

El mapa costs six dollars.

Her entire family habla español.

My brother está pescando.

The bear ya no ha muerto.

Sólo tengo five dollars.

No les han dado an opportunity to leave.

Van a hacer a lot of different activities.

He has una mala reputación.

The earthquake destroyed la ciudad y los suburbios.

The man ate un sándwich de atún.

$\mathrm{Su}$ hermano está training at the gym right now.

The students are prestando atención a la profesora mucho.

Nuestra tía está teaching biology at the high school.

Her colleagues are viendo muchas películas this month.

Sus amigas están going shopping with their mothers this weekend.

Your neighbors are comiendo en ese restaurante ahora mismo.

Susana y él met our uncle.

Lisa and him pidieron dos copas de vino.

Tú y ellos bought some oranges.

You and them compraron unas naranjas.

Esos chicos y ellas started to laugh.

Michael and her conocieron a nuestra tía.

Filler Monolingual English Stimuli

Sometimes he'll go to the store and forget what he was looking for.

We'll hear a sound if someone rings the doorbell.

We'll tell him if we see him.

Who did she say that speaks Spanish?

Who did you think that is fishing? 
What did you believe that has not died yet?

He has a red big balloon.

The earthquake destroyed the ancient beautiful city.

The man ate a meat-free delicious sandwich.

His brother is training at the gym right now.

Our aunt is teaching biology at the high school.

Her friends are going shopping with their mothers this weekend.

Lisa and him ordered two glasses of wine.

You and them bought some oranges.

Michael and her met our aunt.

Filler Monolingual Spanish Stimuli

Todos van a mojarse si llueve hoy.

Ella se esconde cuando él la llama.

Voy a salir si me siento mal.

La gente visita el museo nunca.

José Miguel tiene ningún cuchillo.

El mapa cuesta nada.

David y Diego han ya pedido cinco dólares.

Ellos les han brevemente dado una oportunidad de salir.

Ellos han siempre tenido muchas actividades diferentes.

Los estudiantes están prestando atención a la profesora mucho.

Sus colegas están viendo muchas películas este mes.

Tus vecinos están comiendo en ese restaurante ahora mismo.

Susana y él conoció a nuestro tío.

Tú y ellos compraron unas naranjas.

Esos chicos y ellas empezaron a reírse.

\section{References}

Abney, Steven Paul. 1987. The English Noun Phrase in Its Sentential Aspect. Ph.D. dissertation, Massachusetts Institute of Technology, Cambridge, MA, USA, May 8.

Antón, Eneko, Guillaume Thierry, and Jon Andoni Duñabeitia. 2015. Mixing languages during learning? Testing the one subject-one language rule. PLoS ONE 10: e0130069. [CrossRef] [PubMed]

Avery, Thomas. 2015. The Pedagogical Potential of Codeswitching. Master's Thesis, Daejin University, Pocheon City, Korea, June.

Badiola, Lucia, Rodrigo Delgado, Ariane Sande, and Sara Stefanich. 2018. Code-switching attitudes and their effects on acceptability judgment tasks. Linguistic Approaches to Bilingualism 8: 5-24. [CrossRef]

Belazi, Hedi M., Edward J. Rubin, and Almeida Jacqueline Toribio. 1994. Code switching and X-bar theory: The Functional Head Constraint. Linguistic Inquiry 25: 221-37.

Bullock, Barbara E., and Almeida Jacqueline Toribio. 2009. Themes in the study of code-switching. In The Cambridge Handbook of Linguistic Code-Switching. Edited by Barbara E. Bullock and Almeida Jacqueline Toribio. Cambridge: Cambridge University Press, pp. 1-17.

Chomsky, Noam. 1980. Rules and Representations. Cambridge: MIT Press.

Ebert, Shane, and Bryan Koronkiewicz. 2018. Monolingual stimuli as a foundation for analyzing code-switching data. Linguistic Approaches to Bilingualism 8: 25-66. [CrossRef]

Ellis, Rod. 1994. The Study of Second Language Acquisition. Oxford: Oxford University Press. 
Fernández Fuertes, Raquel, Juana M. Liceras, and Anahí Alba de la Fuente. 2016. Beyond the subject DP versus the subject pronoun divide in agreement switches. In Romance Linguistics 2013: Selected Papers from the 43rd Linguistic Symposium on Romance Languages (LSRL), New York, 17-19 April 2013. Edited by Christina Tortora, Marcel den Dikken, Ignacio L. Montoya and Teresa O'Neill. Amsterdam: Jon Benjamins, pp. 79-98.

Gass, Susan M., Patti Spinner, and Jennifer Behney. 2017. Salience in Second Language Acquisition. Chicago: Routledge. Giancaspro, David. 2015. Code-switching at the auxiliary-VP boundary: A comparison of heritage speakers and L2 learners. Linguistic Approaches to Bilingualism 5: 379-407. [CrossRef]

González-Vilbazo, Kay, Laura Bartlett, Sarah Downey, Shane Ebert, Jeanne Heil, Bradley Hoot, Bryan Koronkiewicz, and Sergio E. Ramos. 2013. Methodological considerations in code-switching research. Studies in Hispanic and Lusophone Linguistics 6: 119-38. [CrossRef]

Gumperz, John J. 1977. The sociolinguistic significance of conversational code-switching. RELC Journal 9: 1-34. [CrossRef]

Hancock, Mark. 1997. Behind classroom code-switching: Layering and language choice in L2 learner interaction. TESOL Quarterly 31: 217-35. [CrossRef]

Kaushanskaya, Margarita, Megan Gross, and Milijana Buac. 2014. Effects of classroom bilingualism on task shifting, verbal memory, and word learning in children. Developmental Science 17: 564-83. [CrossRef] [PubMed]

Klassen, Rachel. 2016. Asymmetric Grammatical Gender Systems in the Bilingual Mental Lexicon. Ph.D. dissertation, University of Ottawa, Ottawa, ON, Canada.

Koronkiewicz, Bryan, and Shane Ebert. forthcoming. Modality in experimental code-switching research: Aural versus written stimuli. In Code-Switching: Theoretical Questions, Experimental Answers. Edited by Luis López. Philadelphia: John Benjamins.

Lee, James F., and Bill VanPatten. 2003. Making Communicative Language Teaching Happen, 2nd ed. New York: McGraw-Hill.

Liceras, Juana M. 2013. Un lugar para cada cosa y cada cosa ... ¿en qué lugar?: La lengua materna, el input y las técnicas de obtención de datos. In Plurilingüismo y Enseñanza de ELE en Contextos Multiculturales: Actas del XXIII Congreso Internacional ASELE. Edited by Beatriz Blecua, Sara Borrell, Berta Crous and Fermín Sierra. Girona: Universitat de Girona, pp. 17-41.

Liceras, Juana M. 2014. Incorporating Second Language Acquisition research into teacher education. In English as a Foreign Language Teacher Education: Current Perspectives and Challenges. Edited by Juan de Dios Martínez Agudo. Amsterdam: Rodopi, pp. 11-33.

Liceras, Juana M., Raquel Fernández Fuertes, Susana Perales, Rocío Pérez-Tattam, and Kenton Todd Spradlin. 2008. Gender and gender agreement in bilingual native and non-native grammars: A view from child and adult functional-lexical mixings. Lingua 118: 827-51. [CrossRef]

Liceras, Juana M., Raquel Fernández Fuertes, and Rachel Klassen. 2016. Language dominance and language nativeness: The view from Spanish-English code-switching. In Spanish-English Code-Switching in the Caribbean and the US. Edited by Rosa E. Guzzardo Tamargo, Catherine M. Mazak and M. Carmen Parafita Couto. Amsterdam: Jon Benjamins, pp. 107-38.

Lipski, John. 1978. Code-switching and the problem of bilingual competence. In Aspects of Bilingualism. Edited by Michel Paradis. Columbia: Hornbeam Press, pp. 250-64.

Littlewood, William. 1981. Communicative Language Teaching: An Introduction. Cambridge: Cambridge University Press.

Macaro, Ernesto. 2005. Codeswitching in the L2 classroom: A communication and learning strategy. In Non-Native Language Teachers. Edited by Enric Llurda. New York: Springer, pp. 63-84.

MacSwan, Jeff. 1999. A Minimalist Approach to Intrasentential Code Switching. New York: Garland.

MacSwan, Jeff, ed. 2014. Programs and proposals in codeswitching research: Unconstraining theories of bilingual language mixing. In Grammatical Theory and Bilingual Codeswitching. Cambridge: MIT Press, pp. 1-33.

Montes-Alcalá, Cecilia. 2001. Written codeswitching: Powerful bilingual images. In Code-Switching Worldwide. Edited by Rodolfo Jacobson. Berlin and Boston: De Gruyter Mouton, pp. 59-74.

Montrul, Silvina, and Roumyana Slabakova. 2003. Competence similarities between native and near-native speakers: An investigation of the preterite/imperfect contrast in Spanish. Studies in Second Language Acquisition 25: 351-98. [CrossRef] 
O'Neill, Robert, Edwin T. Cornelius, and Gay N. Washburn. 1981. American Kernal Lessons: Advanced Student's Book. London: Longman.

Poplack, Shana. 1980. Sometimes I'll start a sentence in Spanish y termino en español: Toward a typology of code-switching. Linguistics 18: 581-618. [CrossRef]

Ravid, Dorit Diskin. 1995. Language Change in Child and Adult Hebrew. New York: Oxford University Press.

Tarone, Elaine E. 1982. Systematicity and attention in interlanguage. Language Learning 32: 69-84. [CrossRef]

Timm, Lenora A. 1975. Spanish-English code-switching: El porque and how-not-to. Romance Philology 28 : 473-82.

Toribio, Almeida Jacqueline. 2001. On the emergence of bilingual code-switching competence. Bilingualism: Language and Cognition 4: 203-31. [CrossRef] 